\title{
The Effects of Velocity and Gradient Changes on Cardiopulmonary Functions during Treadmill Walking
}

\author{
Dongwook Han, PhD, PT ${ }^{1)}$, Haeyoung Lee, PT $^{1)}$, Jonghee Hong, PT $^{1)}$, \\ Misook HA, PhD, PT ${ }^{2)}$, JNUHYEOK JANG, PT ${ }^{3)}$ \\ 1) Department of Physical Therapy, College of Medical and Life Science, Silla University \\ 2) Department of Physical Therapy, ChoonHae College of Health Sciences: Ungchon-myeon, Ulju-gun, \\ Ulsan689-784 Korea.TEL: +82 52-270-0342,FAX: +82 52-270-0249,E-mail: msha@ch.ac.kr \\ 3) Department of Physical Therapy, Jaseng Hospital of Oriental Medicine
}

\begin{abstract}
Purpose] This study investigated the effects of velocity and gradient changes on cardiopulmonary functions during treadmill walking. [Subjects] The subjects were eleven physically fit female participants, 20 to 22 years of age. [Methods] Treadmill workload protocol was set at 4, 5, 6, 7 and $8 \mathrm{~m} / \mathrm{s}$ and $0,2.5,5,7.5$, and $10 \%$ for velocity and gradient loading. A portable gas analyzer (COSMED K4b2, Italy) and portable heart rate analyzer (GBR. A, Finland) measured VO2, VCO2, EE, and HR. A treadmill with control of velocity and gradient was used for walking. Each of the average values used in the analysis was calculated from a 3 to 5 minute use of the treadmill. [Results] During treadmill walking, VO2, VCO2, EE and HR increased as the velocity increased. ALso, as the gradient increased, $\mathrm{VO} 2, \mathrm{VCO} 2, \mathrm{EE}$ and $\mathrm{HR}$ increased. A comparison revealed that changes in velocity had a greater effect on $\mathrm{VO} 2, \mathrm{VCO} 2, \mathrm{EE}$ and HR gradient. [Conclusion] The results show that cardiopulmonary functions are affected by changes in velocity and gradient during walking. In particular, velocity has a greater effect on cardiopulmonary functions than gradient.

Key words: Treadmill, Cardiopulmonary functions, Walking velocity
\end{abstract}

(This article was submitted Feb. 14, 2012, and was accepted Mar. 28, 2012)

\section{INTRODUCTION}

Walking, a basic human movement, is the safest aerobic exercise, and it brings about changes in body composition, enhances motor performance by improving heart rate, blood pressure, and MVO2 (myocardial oxygen consumption), and provides benefits for heart disease ${ }^{1)}$. Walking is also known to improve flexibility and muscular strength, increase bone mineral density, and help psychological issues, for example, by improving cognitive performance ${ }^{2)}$.

Despite these many advantages, the energy expenditure of walking exercise is low compared to that of other types of exercise. Therefore, it is hard for a person with great physical strength to obtain results from walking exercise because the target HR cannot be reached by walking exercise ${ }^{3)}$. To remedy this shortcoming, studies using a treadmill that increases EE (energy expenditure) by applying various workload protocols during walking exercises have been conducted. Kwon Oh-Kyung ${ }^{4}$ ) reported in his study, that the gradient and velocity of a treadmill have great effects on fat loss, while Jeong Il-Gyu et al. ${ }^{5)}$ noted that EE increases when walking with weights on the ankles. Walking exercise is a workload method that is commonly used for ambulation training of patients in hospitals. Nevertheless, not many studies have attempted to determine which variable, velocity or gradient, has the greater effect on changes in cardiopul- monary function.

Accordingly, this study examined the effects of velocity and gradient, major variables of a treadmill, on cardiopulmonary function to determine the more effective variable. The study performed basic research that has not been previously performed.

\section{SUBJECTS AND METHODS}

For this study, 11 female subjects were recruited. The subjects were instructed to walk for five minutes under ten different conditions of velocity and gradient on a treadmill. We made repeated measurements of treadmill walking under each condition, and each measurement was conducted after subjects had rested until their heart rate (HR) had returned to the baseline level. Heart rate was measured using a portable gas analyzer, to ensure the effects of the preceding treatment had disappeared. The measurements of this study were conducted on a treadmill $(\mathrm{h} / \mathrm{p} / \mathrm{Cosmos}$, Proxomed, Germany) with adjustable velocity and gradient. A portable gas analyzer (K4b2, COSMED, Italy), and a portable HR analyzer (GBR. A, Finland) were used.

First, the gradient was set at $0 \%$, and walking was performed at $4,5,6,7$ and $8 \mathrm{~km} / \mathrm{h}$, based on the method employed by several previous studies. Then, the walking velocity was fixed at $4 \mathrm{~km} / \mathrm{h}$, and the gradient was set at 0 , 
Table 1. Verification of $\mathrm{VO} 2$ and $\mathrm{VCO} 2$ consumption, energy expenditure (EE) and heart rate

\begin{tabular}{|c|c|c|c|c|c|c|}
\hline Variable & & Grade1 & Grade2 & Grade3 & Grade4 & Grade5 \\
\hline \multirow{3}{*}{$\begin{array}{l}\mathrm{O} 2 \\
(\mathrm{ml} / \mathrm{min})\end{array}$} & Velocity & $767.87 \pm 183.04$ & $875.43 \pm 156.99$ & $1030.13 \pm 155.89$ & $1261.94 \pm 250.89$ & $1599.98 \pm 296.88$ \\
\hline & Gradient & $767.87 \pm 183.04$ & $867.08 \pm 200.49$ & $929.51 \pm 174.38$ & $1094.83 \pm 251.84$ & $1119.5 \pm 200.66$ \\
\hline & \multicolumn{2}{|c|}{ Within Group : $\mathrm{F}=68.986^{*}$} & Between Group : 4.218 & \multicolumn{2}{|c|}{$8 \quad$ Interaction : $\mathrm{F}=11.901^{*}$} & \\
\hline \multirow{3}{*}{$\begin{array}{l}\mathrm{CO} 2 \\
(\mathrm{ml} / \mathrm{min})\end{array}$} & Velocity & $613.94 \pm 240.84$ & $758.36 \pm 176.04$ & $916.15 \pm 146.07$ & $1118.49 \pm 341.78$ & $1603.65 \pm 200.02$ \\
\hline & Gradient & $613.94 \pm 240.84$ & $711.57 \pm 164.56$ & $779.06 \pm 166.33$ & $815.43 \pm 205.87$ & $905.38 \pm 168.53$ \\
\hline & \multicolumn{2}{|c|}{ Within Group : $F=43.573^{*}$} & \multicolumn{3}{|c|}{ Between Group : 14.879* Interaction } & \\
\hline \multirow{3}{*}{$\begin{array}{l}\mathrm{EE} \\
(\mathrm{kcal} / \mathrm{min})\end{array}$} & Velocity & $3.70 \pm 0.90$ & $4.25 \pm 0.80$ & $5.03 \pm 0.74$ & $6.32 \pm 1.18$ & $8.03 \pm 1.35$ \\
\hline & Gradient & $3.70 \pm 0.90$ & $4.16 \pm 0.95$ & $4.45 \pm 0.86$ & $5.15 \pm 1.19$ & $5.35 \pm 0.93$ \\
\hline & \multicolumn{2}{|c|}{ Within Group : $\mathrm{F}=82.631^{*}$} & Between Group : $6.552^{*}$ & \multicolumn{2}{|c|}{ Interaction $: \mathrm{F}=17.178^{*}$} & \\
\hline \multirow{3}{*}{$\begin{array}{l}\text { HR } \\
(\mathrm{bpm})\end{array}$} & Velocity & $106.51 \pm 12.76$ & $113.36 \pm 11.70$ & $121.52 \pm 12.49$ & $135.10 \pm 17.56$ & $157.27 \pm 8.62$ \\
\hline & Gradient & $106.51 \pm 12.76$ & $111.64 \pm 13.24$ & $112.61 \pm 9.87$ & $116.45 \pm 8.29$ & $122.82 \pm 9.34$ \\
\hline & \multicolumn{2}{|c|}{ Within Group : $\mathrm{F}=46.256^{*}$} & \multicolumn{3}{|c|}{$* \quad$ Interaction $: \mathrm{F}=14.118^{*}$} & \\
\hline
\end{tabular}

(Unit) *Statistically significant at the level of $\mathrm{p}<0.05$

$2.5,5,7.5$, and $10 \%$, according to the method of previous studies. Velocity and gradient were divided into five levels. Each subject was instructed to walk on the treadmill at the five velocities and five gradients for five minutes ${ }^{6}$.

Subjects wore the portable gas analyzer and walked for five minutes at each of the set velocities with the gradient fixed at $0 \%$. They rested after each 5-minute walk, and then walked again for five minutes at the next level of velocity. While resting, their HR was measured before walking again to ensure that HR had returned to the stable condition. For the analysis, these measurements are referred to as the velocityload group. Subjects took a one-week rest to recover from walking fatigue, and then repeated the procedure at each of the five gradients with the velocity fixed at $4 \mathrm{~km} / \mathrm{h}$. For the analysis, these measurements are referred to as the gradientload group. For gas analysis and HR, the average values of respiratory gas and HR between the third and fifth minutes of walking, when the body reached a steady state, were used ${ }^{7)}$.

Repeated measures ANOVA was used to analyze the data for the effect of velocity and gradient.

\section{RESULTS}

The subjects of this study were physically fit female students of S University in Busan who had never been diagnosed with cardiopulmonary diseases. Their average age was 21.73 years old, and their average height and weight were $161.55 \mathrm{~cm}$ and $51.45 \mathrm{~kg}$, respectively.

According to the measurement of $\mathrm{VO} 2$ at each level of velocity and gradient during walking on the treadmill, in the velocity-load group, VO2 was $767.87 \mathrm{~mL} / \mathrm{min}, 875.43 \mathrm{~mL} /$ $\mathrm{min}, 1030.13 \mathrm{~mL} / \mathrm{min}, 1261.94 \mathrm{~mL} / \mathrm{min}$, and $1599.98 \mathrm{~mL} /$ $\min$ at $4,5,6,7$, and $8 \mathrm{~km} / \mathrm{h}$, respectively $(\mathrm{p}<0.05)$. In the gradient-load group, VO2 was $767.87 \mathrm{~mL} / \mathrm{min}, 867.08 \mathrm{~mL} /$ $\mathrm{min}, 929.51 \mathrm{~mL} / \mathrm{min}, 1094.83 \mathrm{~mL} / \mathrm{min}$, and $1119.5 \mathrm{~mL} / \mathrm{min}$ at $0,2.5,5,7.5$, and $10 \%$, respectively $(\mathrm{p}<0.05)$. The results indicate that $\mathrm{VO} 2$ increased as the workload increased in both groups. According to the comparison of $\mathrm{VO} 2$ change in the two groups, $\mathrm{VO} 2$ in the velocity-load group increased more than in the gradient-load group. According to the measurement of $\mathrm{VCO} 2$ at each level of velocity and gradient during walking on the treadmill, in the velocityload group, VCO2 was $613.94 \mathrm{~mL} / \mathrm{min}, 758.36 \mathrm{~mL} / \mathrm{min}$, $916.15 \mathrm{~mL} / \mathrm{min}, 1118.49 \mathrm{~mL} / \mathrm{min}$, and $1063.65 \mathrm{~mL} / \mathrm{min}$ at $4,5,6,7$, and $8 \mathrm{~km} / \mathrm{h}$, respectively $(\mathrm{p}<0.05)$. In the gradientload group, VCO2 was $613.94 \mathrm{~mL} / \mathrm{min}, 711.57 \mathrm{~mL} / \mathrm{min}$, $779.06 \mathrm{~mL} / \mathrm{min}, 815.43 \mathrm{~mL} / \mathrm{min}$, and $905.38 \mathrm{~mL} / \mathrm{min}$ at 0 , $2.5,5,7.5$, and $10 \%$, respectively $(\mathrm{p}<0.05)$. In both groups, $\mathrm{VCO} 2$ increased as the workload increased. According to the comparison of $\mathrm{VCO} 2$ changes in the two groups, $\mathrm{VCO} 2$ increased significantly more in the velocity-load group than in the gradient-load group. According to the measurement of EE at each level of velocity and gradient during walking on the treadmill, in the velocity-load group, EE was $3.7 \mathrm{kcal} / \mathrm{min}, 4.25 \mathrm{kcal} / \mathrm{min}, 5.03 \mathrm{kcal} / \mathrm{min}, 6.32 \mathrm{kcal} / \mathrm{min}$, and $8.03 \mathrm{kcal} / \mathrm{min}$ at $4,5,6,7$, and $8 \mathrm{~km} / \mathrm{h}$, respectively $(\mathrm{p}<0.05)$. In the gradient-load group, EE was $3.7 \mathrm{kcal} / \mathrm{min}$, $4.16 \mathrm{kcal} / \mathrm{min}, 4.45 \mathrm{kcal} / \mathrm{min}, 5.15 \mathrm{kcal} / \mathrm{min}$, and $5.35 \mathrm{kcal} /$ min at $0,2.5,5,7.5$, and $10 \%$, respectively $(\mathrm{p}<0.05)$. In both groups, EE per minute increased as the workload increased. According to the comparison of EE per minute in the two groups, it increased more in the velocity-load group than in the gradient-load group. According to the measurement of $\mathrm{HR}$ at each level of velocity and gradient during walking on the treadmill, in the velocity-load group, HR was 106.51 bpm, $111.36 \mathrm{bpm}, 121.52 \mathrm{bpm}, 135.1 \mathrm{bpm}$, and 157.27 bpm at $4,5,6,7$, and $8 \mathrm{~km} / \mathrm{h}$, respectively $(\mathrm{p}<0.05)$. In the gradient-load group, HR was $106.51 \mathrm{bpm}, 111.64 \mathrm{bpm}$, $112.6 \mathrm{bpm}, 116.45 \mathrm{bpm}$, and $122.82 \mathrm{bpm}$ at $0,2.5,5,7.5$, and $10 \%$, respectively $(\mathrm{p}<0.05)$. In both groups, HR increased as the workload increased. According to the comparison of HR in the two groups, HR increased significantly more in the velocity-load group than in the gradient load-group (Table $1)$.

\section{DISCUSSION}

In cardiovascular responses to exercise, the distribution of cardiac output changes, and cardiopulmonary function increases according to the changes in the metabolism of 
each part of the body ${ }^{8)}$. In the present study, the velocity and gradient were divided according to the range that could be used for walking exercise on the treadmill in order to examine the effects of each level of the two variables on cardiopulmonary function and to determine which workload variable had the greater effect on cardiopulmonary function.

Jeong Il-Gyu et al. ${ }^{5}$ reported in their study that oxygen intake increased as the velocity of the treadmill increased in both groups, and HR and EE showed statistically significant increases at $7 \mathrm{~km} / \mathrm{h}$. In the study by Jo Ki-Sun et al. ${ }^{9}$, the effects of gradient on forward walking and backward walking were observed. Their results show that VO2 and HR increased with increases in gradient regardless of the direction of walking.

In the present, all of the values measured to determine the effects of the velocity on cardiopulmonary function, namely $\mathrm{VO} 2, \mathrm{VCO} 2, \mathrm{EE}$, and $\mathrm{HR}$, increased as the velocity increased from 4 to $8 \mathrm{~km} / \mathrm{h}$. This result is in agreement with to the results of previous studies in that the changes in cardiopulmonary function become greater as the velocity increased. As the gradient of the treadmill increased, all of $\mathrm{VO} 2, \mathrm{VCO} 2, \mathrm{EE}$, and $\mathrm{HR}$ increased as the gradient increased from 0 to $10 \%$. This result is also similar to the results of other studies in which tests were conducted with gradual increases in the gradient. However, in the comparison of the effects of velocity and gradient, $\mathrm{VO} 2, \mathrm{VCO} 2, \mathrm{EE}$, and $\mathrm{HR}$ increased more with increases in velocity. In other words, the changes of velocity had greater effects than those of gradient. However, there are limits to general comparisons of velocity and gradient, and standardized studies of velocity and gradient should be conducted in the future.

\section{REFERENCES}

1) Gill JM, Frayn KN, Wootton SA, et al.: Effects of prior moderate exercise on exogenous and endogenous lipid metabolixm and plasma factor VII activity. Clin Sci, 2001, 100: 517-527. [Medline] [CrossRef]

2) Murphy M, Nevill A, Neville C, et al.: Accumulating brisk walking for fitness, cardiovascular risk, and psychological health. Med Sci Sports Exerc, 2002, 34: 1468-1474. [Medline] [CrossRef]

3) Kwon YG, Baek WS, Lee SI, et al.: The effect of rope-jumping exercise on body fat $\%, \mathrm{VO} 2 \mathrm{max}$ and serum lipids level in obese students in the long term. J Sports Leis Stud, 2001, 15: 425-435.

4) Kwon OK: Analysis of the thermic effect of excercise (TEE) according to the body composition and the treadmill speed in college women. Ewha University, Dissertation of Doctorate Degree, 2002.

5) Jeong IG, Yoon JH, Kim YP, et al.: Effects of leg-weight loading on energy expenditure and heart rate response during gradual speed treadmill walking exercise. J Kor Sports Med, 2003, 21: 184-191.

6) Choi DH, Choi HN, Jun TW: Exercise physiology 6th ed. Seoul: Life Sciences, 2008.

7) Kim SH, Yoon JH, Lee HH: Analysis of energy expenditure according to variable speed and stride length during treadmill walking. J Kor Sports Med, 2005, 23: 293-299.

8) Stuart M, Benenuti F, Macko R, et al.: Community-based adaptive physical activity program for chronic stroke. Neurorehabil Neural Repair, 2009, 23: 726-734. [Medline] [CrossRef]

9) Jo KS, Lee DT: Energy cost and cardiorespiratory responses during inclined forward and backward walking. Korean J Sport Sci, 2005, 14: $36-43$. 